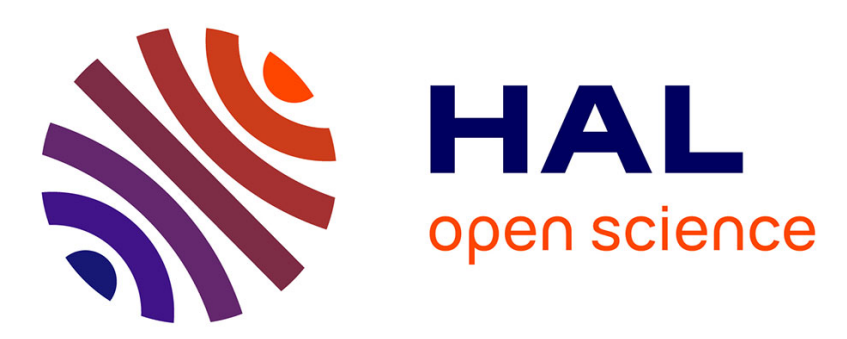

\title{
Platelike MFI Crystals with Controlled Crystal Faces Aspect Ratio
}

Weijiong Dai, Cassandre Kouvatas, Wenshu Tai, Guangjun Wu, Naijia Guan, Landong Li, Valentin Valtchev

\section{- To cite this version:}

Weijiong Dai, Cassandre Kouvatas, Wenshu Tai, Guangjun Wu, Naijia Guan, et al.. Platelike MFI Crystals with Controlled Crystal Faces Aspect Ratio. Journal of the American Chemical Society, 2021, 143 (4), pp.1993-2004. 10.1021/jacs.0c11784 . hal-03418575

HAL Id: hal-03418575

https://hal.science/hal-03418575

Submitted on 7 Nov 2021

HAL is a multi-disciplinary open access archive for the deposit and dissemination of scientific research documents, whether they are published or not. The documents may come from teaching and research institutions in France or abroad, or from public or private research centers.
L'archive ouverte pluridisciplinaire HAL, est destinée au dépôt et à la diffusion de documents scientifiques de niveau recherche, publiés ou non, émanant des établissements d'enseignement et de recherche français ou étrangers, des laboratoires publics ou privés. 


\title{
Plate-like MFI Crystals with Controlled Crystal Faces Aspect Ratio
}

Weijiong Dai, ${ }^{1,2}$ Cassandre Kouvatas, ${ }^{2}$ Wenshu Tai, ${ }^{1}$ Guangjun Wu, ${ }^{1 *}$ Naijia Guan,,${ }^{1}$ Landong $\mathrm{Li},{ }^{1}$ and Valentin Valtchev ${ }^{2,3 *}$

${ }^{1}$ School of Materials Science and Engineering \& National Institute for Advanced Materials, Nankai University, Tianjin 300350, P.R. China

${ }^{2}$ Qingdao Institute of Bioenergy and Bioprocess Technology, Chinese Academy of Sciences, 189 Songling Road, Laoshan District, Qingdao, Shandong 266101, P. R. China

${ }^{3}$ Laboratoire Catalyse et Spectrochimie, Normandie Univ, ENSICAEN, UNICAEN, CNRS, 6 Boulevard Maréchal Juin, 14050 Caen, France

\begin{abstract}
Zeolite crystals offering a short diffusion pathway through the pore network are highly desired for a number of catalytic and molecule separation applications. Herein, we develop a simple synthetic strategy toward reducing the thickness along $b$-axis of MFI-type crystals, thus providing a short diffusion path along the straight channel. Our approach combines preliminary aging and a fluoride-assisted low-temperature crystallization. The synthesized MFI crystals are in the micron-size range along $a$ - and $c$-axis, while the thickness along the $b$-axis is a few tens of nanometers. The synthesis parameters controlling the formation of plate-like zeolite are studied, and the factors controlling the zeolite growth identified. The synthesis strategy works equally well with all-silica MFI (silicalite-1) and its Al- and Ga-containing derivatives. The catalytic activity of plate-like ZSM-5 in the methanol-to-hydrocarbons (MTH) reaction is compared with a commercial nano-sized ZSM-5 sample, as the plate-like ZSM-5 exhibits a substantially extended lifetime. The synthesis of plate-like MFI crystals is successfully scaled up to a kilogram scale.
\end{abstract}

Keywords: Zeolite; Morphology; Ultra-thin crystals; Catalysis 


\section{Introduction}

Zeolites are initially discovered as minerals in sediment and pegmatite rocks. ${ }^{1}$ Natural zeolites are mainly used in agriculture, water, and soil remediation, while their synthetic counterparts have diverse industrial applications, as heterogeneous catalysis and molecular sieving are the major industrial fields of use. ${ }^{2,3}$ More than $40 \%$ of acid-catalyzed reactions are currently based on synthetic zeolites. ${ }^{4}$ The great success of zeolites in catalysis is related to their unique structural features, i.e., the ordered channels of molecular dimensions and the presence of modulable active sites. ${ }^{5}$ However, the narrow channels of zeolite impose a significant restriction on the transport of molecules, causing an increase in the secondary reactions as well as the subsequent catalyst deactivation by coking. ${ }^{5-8}$

The diffusional problems can be partially circumvented by reducing the path length through the zeolite crystal. The two strategies employed to reduce the diffusion path in zeolites are the decrease of the crystals to the nano-sized range ${ }^{9-12}$, and the introduction of larger secondary (meso-/macro-) pores in the crystals. ${ }^{13-15}$ Zeolites comprising a secondary pore system, which serves as highways for reactants and products, are often called hierarchical, and their preparation is usually complex. ${ }^{14,16}$ The synthesis of zeolite nanocrystals also has a downside as the specific synthesis conditions and complex product processing are required. ${ }^{9}$ An alternative solution that could solve the problem with the diffusion limitations in zeolites without using additional treatments, as in the case of hierarchical and nano zeolites, is the synthesis of micron-sized zeolites with particular morphology. More precisely, the control of zeolite morphology could be used to limit the growth in the direction along the channel system of interest, thus shortening the diffusion pathway. Tuning zeolite morphology could also allow developing the face where the channel system of interest is presented on the zeolite surface, thus increasing the number of pore opening per unit crystals surface. This strategy is particularly important in preparing zeolites with a biased performance of different channel systems. For instance, MFI-type material, used in various catalytic and separation processes, contains straight and zig-zag channel systems running along $b$ and $a$ crystal axis, respectively (Figure S1). Shortening the diffusion path along the straight channel ( $b$-axis) changes zeolite performance substantially. ${ }^{17-20}$

An ultimate example of this strategy was the preparation of zeolite nanosheets, first prepared by Ryoo 
and co-workers. ${ }^{8}$ Ryoo's group decreased the thickness of MFI-type zeolite along the $b$-axis to one unit cell. Nanosheet-like zeolites focused zeolite community's attention with remarkable catalytic performance in several reactions, ${ }^{21-25}$ and superior separation ability in membrane applications. ${ }^{20,26,27}$ However, these zeolitic materials are synthesized by using the complex and expensive structure-directing agents (SDAs), ${ }^{28-30}$ or by tedious swelling, pillaring, and exfoliation procedures. ${ }^{31}$ The size of the zeolite nanosheet is usually tiny (100-200 nm in length), and the handling is even more complex than the conventional nano-zeolites.

From a practical point of view, the synthesis of zeolite crystals with morphology that enhances the transport through a particular channel system without using an exotic SDA is highly desired. The aspect ratio between different crystal faces should be changed in a way to minimize the length of the channel. Maximizing the face's size where the channel system of interest appears on the crystal surface is also important. Keeping the zeolite crystal size in the micrometer range and decreasing the size to a few tens of nanometers in a particular crystallographic direction has significant practical value. Such crystals can be processed employing the conventional post-synthetic protocols and do not require any additional treatments.

Previously studies have demonstrated that adjusting synthesis parameters or adding synthesis modifiers could substantially change zeolite crystal morphology. ${ }^{32-37}$ For instance, long to short prismatic LTL-type crystals were synthesized by simple changing of water content in the synthesis gel. ${ }^{33}$ The zeolite Beta morphology was controlled, varying the $\mathrm{pH}$ of the system. ${ }^{35}$ Crystals with well-developed pyramidal (h0l) or pinacoidal (001) faces were obtained. For instance, at high $\mathrm{pH}$ plate-like zeolite Beta with a pinacoidal face dominating crystal morphology was obtained. The use of additives can also effectively tailor the aspect ratio of zeolite crystals. Different types of additives, including alcohol, ${ }^{38,39}$ tributylphosphine oxide $^{40}$ graphene oxide $^{41}{ }^{\text {peptoids }},{ }^{42}$ and amino acid arginine, ${ }^{43}$ were employed to modify crystal morphology of different types of zeolites. Although some positive results were published, a dramatic change in the aspect ratio between different faces was not reported to the best of our knowledge. None of these studies guide how one can tune the crystal morphology to nano-size range in a particular crystallographic direction.

Fluorine ion $\left(\mathrm{F}^{-}\right)$is the alternative $\mathrm{OH}^{-}$as a mineralizing agent in zeolite synthesis. ${ }^{44,45}$ It is usually 
used in the synthesis of high- or all-silica zeolites in a quasi-neutral medium. It was reported that fluoride could also be used to achieve the oriented growth of thin zeolite films. ${ }^{46}$ Hence, we selected the ammonium fluoride $\left(\mathrm{NH}_{4} \mathrm{~F}\right)$ as a zeolite synthesis modifier to change the crystal face aspect ratio between the faces of the crystals.

The present study aims to obtain ultra-thin zeolite plates, keeping the other crystals dimension in the micron-size range. Fulfilling this goal would provide a relevant approach to zeolites with improved accessibility and decreased diffusion limitations, avoiding the use of complex organic structure-directing agents (SDA) and multi-step procedures. Our approach is exemplified by preparing MFI-type crystals with controllable aspect ratios between different crystal faces. We selected the MFI-type zeolite because it is an industrially relevant zeolite, ${ }^{47}$ and exhibits two different channel systems, highlighting the effect of crystal morphology on zeolite accessibility and transport through the channels.

\section{Results and discussion}

Substantial preliminary work has been executed to adjust the ratio between different reactants and pre-synthesis aging conditions. The reference, $\mathrm{NH}_{4} \mathrm{~F}$-free synthesis, with a molar composition of 0.1 TPAOH: $1.0 \mathrm{SiO}_{2}: 30 \mathrm{H}_{2} \mathrm{O}$ was performed at $90{ }^{\circ} \mathrm{C}$ for $72 \mathrm{~h}$ under static condition. A highly crystalline product was obtained (Figure S2f). The crystal size was close to $1 \mu \mathrm{m}$, as each crystal contained a $90^{\circ}$ twin crystal, a morphological feature often observed for the MFI-type material (Figure S3a). The impact of $\mathrm{NH}_{4} \mathrm{~F}$ on the MFI crystal morphology was studied with a gel of composition $0.1 \mathrm{TPAOH}: 1.0 \mathrm{SiO}_{2}$ : $0.8 \mathrm{NH}_{4} \mathrm{~F}: 30 \mathrm{H}_{2} \mathrm{O}$ (see Supporting Information for details). This system yielded well-shaped, very thin plate-like crystals. The XRD pattern, Ar physisorption analysis, and representative TEM and SEM images of the crystals are shown in Figure 1. The product was highly crystalline, according to the XRD study (Figure 1a). This result was confirmed by the type I physisorption isotherm, with fast uptake at low relative pressure, characteristic of a zeolite type material (Figure 1b). The micropore volume $(0.14$

$\left.\mathrm{cm}^{3} / \mathrm{g}\right)$ and specific surface area $\left(430 \mathrm{~m}^{2} / \mathrm{g}\right)$ of the plate-like MFI zeolite crystals are characteristic of highly crystalline MFI-type material (Table S1). The high crystallinity of the single-crystalline plate-like zeolite is also illustrated by the well-defined lattice fringes and the selected area electron diffraction 
(SAED) pattern in the HR-TEM image (Figure 1f and 1g). Microscopy study (Figure 1c, 1d and 1e) reveals that crystals' length-width dimensions are in the micron scale. Meanwhile, the thickness of the obtained crystals was $\sim 100 \mathrm{~nm}$. Thus, the crystals are well-shaped with developed (100) and (0kl) faces, while the (010) face is very short. In the enlarged view HAADF-STEM image (Figure 1f), the zeolite channels along the b-axis can be clearly observed.
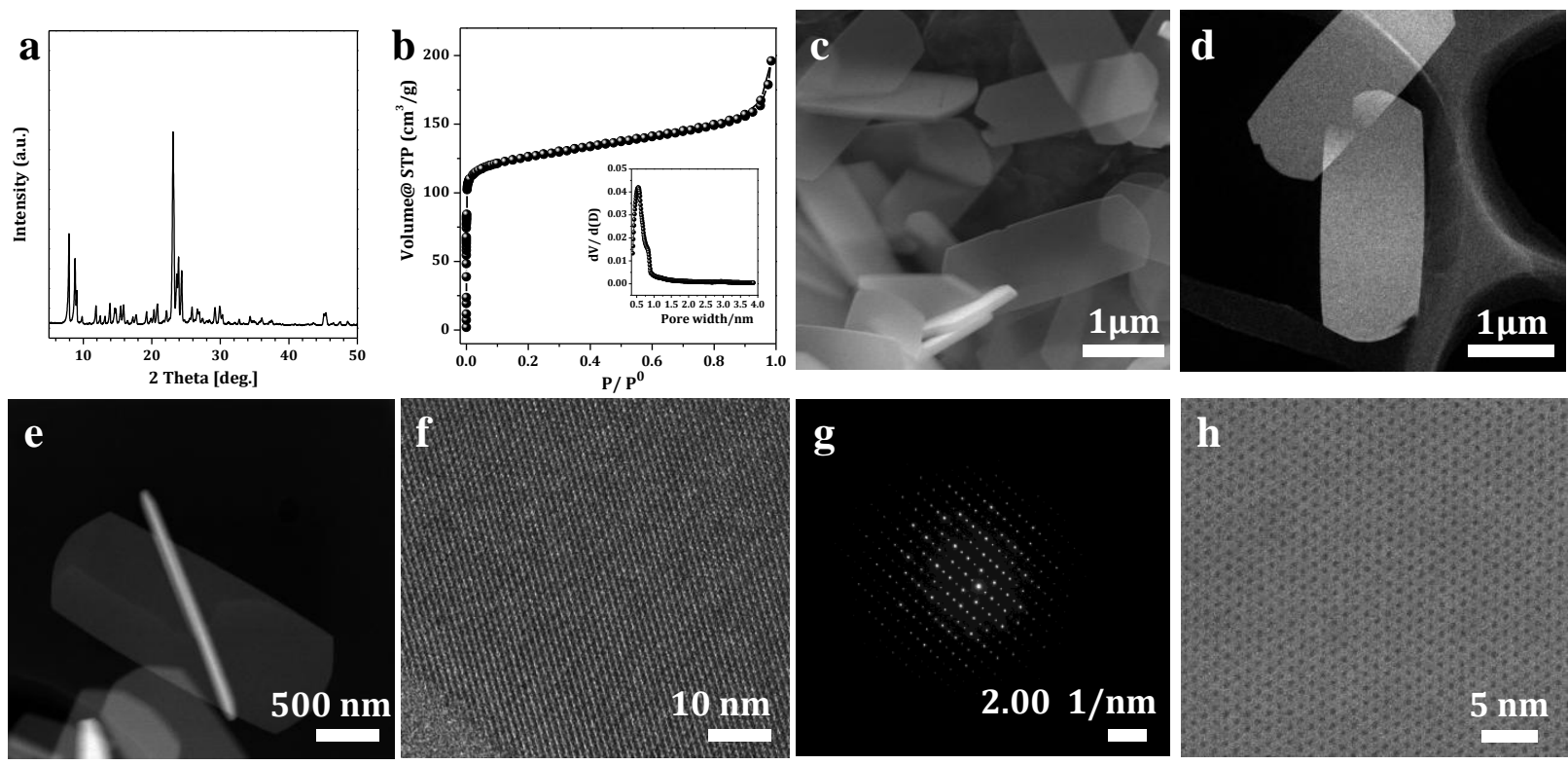

Figure 1. General features of silicalite-1 obtained in the $0.1 \mathrm{TPAOH}: 1.0 \mathrm{SiO}_{2}: 0.8 \mathrm{NH}_{4} \mathrm{~F}: 30 \mathrm{H}_{2} \mathrm{O}$ system: (a) XRD pattern of as-synthesized solid products; (b) Ar physisorption isotherm of the calcined product with pore size distribution shown as an inset; (c) SEM and (d, e) low-magnification HAADF-STEM images of silicalite-1 crystals; (f) high-resolution TEM images, (g) the selected area electron diffraction (SAED) pattern; (h) high-magnification HAADF-STEM image of silicalite-1 crystals after calcination.

A systematic study of the ammonium fluoride content on the MFI morphology was performed using the system: 0.1 TPAOH: $1.0 \mathrm{SiO}_{2}: \mathrm{y} \mathrm{NH}_{4} \mathrm{~F}: 30 \mathrm{H}_{2} \mathrm{O}$, where y was varied between 0 and 1.6. The morphology of twin crystals obtained without $\mathrm{NH}_{4} \mathrm{~F}$ (Figure $\mathrm{S} 3 \mathrm{a}$ ) changed gradually with the increase of $\mathrm{NH}_{4} \mathrm{~F}$ content in the gel. The most noticeable change was the disappearance of $90^{\circ}$ twin crystal (Figure S3d). The other significant change was the change of the aspect ratio between (010) and (100) faces. This effect is a consequence of the decrease in the size of (100) face. The increase of y value to 1.2 and 1.6 further accentuated the morphological changes of MFI-type material, as crystal's thickness reached several tens of nanometers (Figure S3e and S3f). Noteworthy, the crystals synthesized in the 
$\mathrm{NH}_{4} \mathrm{~F}$-containing medium are larger than that of the reference sample. Thus, the silicalite- 1 crystals grow from $\sim 700 \mathrm{~nm}$ to $\sim 3000 \mathrm{~nm}$ along the $c$-axis, at the same time decreasing the thickness from $\sim 500$ $\mathrm{nm}$ to $\sim 100 \mathrm{~nm}$ along the $b$-axis (Figure 2a). These morphological changes are better presented via the aspect ratio between different faces. The ratio between $c$ - and $a$-axis $\left(\mathrm{L}_{c} / \mathrm{L}_{\mathrm{a}}\right)$ as well as between $c$ - and $b$-axis $\left(\mathrm{L}_{\mathrm{c}} / \mathrm{L}_{\mathrm{b}}\right)$ was used to evaluate the changes in the $(100)$ and $(010)$ faces, where the pore mouths of zig-zag and straight channel appears on the surface, respectively. The $\mathrm{L}_{c} / \mathrm{L}_{\mathrm{b}}$ aspect ratio increased from $\sim 2.5$ to $\sim 26$, when $\mathrm{NH}_{4} \mathrm{~F}$ content in the gel changed from 0 to 1.6 (Figure 2c). At the same time, as can be observed from Figure $2 b$, the change in the $L_{c} / L_{a}$ was not dramatic (from $\sim 1.3$ to $\sim 2.7$ ), revealing that the growth in $b$ direction was greatly affected by the $\mathrm{NH}_{4} \mathrm{~F}$ addition. The zeolite crystallinity also depends on the $\mathrm{NH}_{4} \mathrm{~F}$ content in the gel, as can be seen in Figure $\mathrm{S} 2$. At low $\mathrm{NH}_{4} \mathrm{~F}$ content $(\mathrm{y}=0.05$ and 0.2), an amorphous phase containing a few MFI crystals was observed, even though the crystallization was extended to $168 \mathrm{~h}$ (Figure S3b and S3c). In contrast, a highly crystalline product was obtained within $72 \mathrm{~h}$ when y increased to 0.8 . Further increasing y to 1.2 and 1.6 shortens the crystallization time to $48 \mathrm{~h}$ and $24 \mathrm{~h}$, respectively. However, it did not bring substantial change in the crystalline product (Figure S3e and S3f), showing a threshold of $\mathrm{NH}_{4} \mathrm{~F}$ concentration, after which the morphology is not impacted. The best result in terms of high $\mathrm{L}_{\mathrm{c}} / \mathrm{L}_{\mathrm{b}}$ aspect ratio and short crystallization time was obtained with $\mathrm{y}=0.8$. In this case, the average crystal thickness along $b$-axis was $\sim 100 \mathrm{~nm}$, and the crystalline product was obtained within $72 \mathrm{~h}$. The set of experimental results unambiguously shows that the $\mathrm{NH}_{4} \mathrm{~F}$ concentration has a direct effect on the MFI crystal growth, including both the crystallization kinetics and the crystal morphology.

It should be noted the effect of the $90{ }^{\circ} \mathrm{C}$ aging prior to the addition of $\mathrm{NH}_{4} \mathrm{~F}$ to the gel, which plays a crucial role in the formation of plate-like MFI zeolite crystals. Without this aging step, the gel with a similar molar composition (0.1 TPAOH: $1.0 \mathrm{SiO}_{2}: 0.8 \mathrm{NH}_{4} \mathrm{~F}: 30 \mathrm{H}_{2} \mathrm{O}$ ) did not yield crystalline material up to $168 \mathrm{~h}$ crystallization (Figure 2e). In order to get an insight into the $90{ }^{\circ} \mathrm{C}$ aging on gel structure, we performed IR analysis. The FTIR spectra of the samples collected after aging at $90{ }^{\circ} \mathrm{C}$ for $12 \mathrm{~h}$ are shown in Figure S4. Compared to the amorphous silica, the sample taken after $12 \mathrm{~h}$ exhibits a broad band at $\sim 550-570 \mathrm{~cm}^{-1}$, which reveals that elements of pentasil structure are already present in the solid. $^{48}$ Increasing the aging time from 12 to 24 and $36 \mathrm{~h}$ changed the growth rate, and thus the 
crystallization time was reduced to $72 \mathrm{~h}, 36 \mathrm{~h}$ and $24 \mathrm{~h}$, respectively. However, $90^{\circ}$ twin crystals were yielded instead of single plate-like crystals when the aging time was extended to 24 and 36 h (Figure 2e).

It is known that the aging process impacts zeolite nucleation and thus crystal growth. ${ }^{49}$ In this work, the aging step was necessary to obtain MFI crystals in the $\mathrm{NH}_{4} \mathrm{~F}$ containing gel as $12 \mathrm{~h}$ was the optimal aging time yielding very thin plate-like crystals. The crystal morphology is impacted by the species generated during the aging process. We anticipate that the plate-like morphology is a consequence of a high concentration of precursors species with similar development and a particular mechanism of oriented aggregation, which leads to the preferential growth along the $a$ - and $c$-axis, and results in a highly developed (010) face. However, the intimate mechanism laying behind this particular growth is difficult to be elucidated.

The impact of the SDA content on the crystal morphology was studied using the system: $\mathrm{x}$ TPAOH: 1.0 $\mathrm{SiO}_{2}: 0.8 \mathrm{NH}_{4} \mathrm{~F}: 30 \mathrm{H}_{2} \mathrm{O}$, where $\mathrm{x}$ was varied in the range of 0.08-0.35. As shown in Figure $\mathrm{S} 5$, with the increase of SDA content, MFI crystals' size decreased. This is the expected effect due to the more abundant nucleation in TPA-rich systems. ${ }^{11}$ Meanwhile, a decrease from $\sim 30$ to $\sim 20$ of the $\mathrm{L}_{\mathrm{c}} / \mathrm{L}_{\mathrm{b}}$ ratio can be observed when $\mathrm{x}$ is below 0.125 . After that, no change of the $\mathrm{L}_{\mathrm{c}} / \mathrm{L}_{\mathrm{b}}$ ratio was detected (Figure S6). However, the $\mathrm{L}_{\mathrm{c}} / \mathrm{L}_{\mathrm{a}}$ was not influenced too much by the SDA concentration. It remained in the range of 1.8-2.8 (Figure S6). The decrease of the overall crystal dimension resulted in much thinner along $b$-axis crystals. Thus crystallites with an impressive thickness of $\sim 10 \mathrm{~nm}$ along the $b$-axis without using any organic modifier were obtained (Figure $2 \mathrm{~d}$ and S5). These results show that the SDA content has a limited influence on the aspect ratio between different faces. However, the TPAOH content exhibits a noticeable impact on the crystallinity zeolite products, as shown in Figure $2 \mathrm{~d}$. For instance, at $\mathrm{x}=0.08$, the relative crystallinity of $72 \mathrm{~h}$ synthesized sample is $\sim 63 \%$. It can be improved by extending the crystallization time to $120 \mathrm{~h}$ (Figure S7). Increasing x from 0.08 to 0.35 led to highly crystalline zeolite crystals, which was obtained within $72 \mathrm{~h}$.

As MFI-type zeolites are often synthesized at elevated temperatures $\left(\mathrm{T} \geq 150{ }^{\circ} \mathrm{C}\right)$, we have studied the impact of synthesis temperature on the morphology of the plate-like crystals. Noteworthy, plate-like MFI crystals can be obtained over a temperature range of $90-180{ }^{\circ} \mathrm{C}$ using the system $0.1 \mathrm{TPAOH}: 1.0$ 
$\mathrm{SiO}_{2}$ : $0.8 \mathrm{NH}_{4} \mathrm{~F}$ : $30 \mathrm{H}_{2} \mathrm{O}$ (Figure $\mathrm{S} 8$ ). As shown in Figure $\mathrm{S} 8$ and $\mathrm{S}$, increasing the crystallization temperature from 90 to $180{ }^{\circ} \mathrm{C}$ resulted in a slight increase in the crystal size. Thus the length along the $c$-axis changed from $\sim 2600 \mathrm{~nm}$ to $\sim 3500 \mathrm{~nm}$, while along the $b$-axis, the increase was only from $\sim 100$ $\mathrm{nm}$ to $\sim 150 \mathrm{~nm}$. Meanwhile, the length along $a$-axis did not show any obvious change. Consequently, the aspect ratios, $\mathrm{L}_{\mathrm{c}} / \mathrm{L}_{\mathrm{a}}$ and $\mathrm{L}_{\mathrm{c}} / \mathrm{L}_{\mathrm{b}}$, remained nearly unchanged (Figure $\mathrm{S} 9 \mathrm{~d}$ ). Thus the crystallization temperature shows a weak influence on the aspect ratio between different crystal faces. The corresponding relative crystallinity increased from $\sim 85$ to $\sim 100 \%$, with the temperature rising from $90{ }^{\circ} \mathrm{C}$ to $180{ }^{\circ} \mathrm{C}$ (Figure S9a).

Summarizing the set of experimental results, one can state that an aging step of $12 \mathrm{~h}$ generating nuclei in the system before the addition of $\mathrm{NH}_{4} \mathrm{~F}$ is indispensable for the formation of plate-like MFI crystals. Further, with precise control of $\mathrm{NH}_{4} \mathrm{~F}$ content and tuning the synthesis parameters, single-crystalline plate-like MFI zeolite with adjustable thickness can be obtained (Figure 2). 

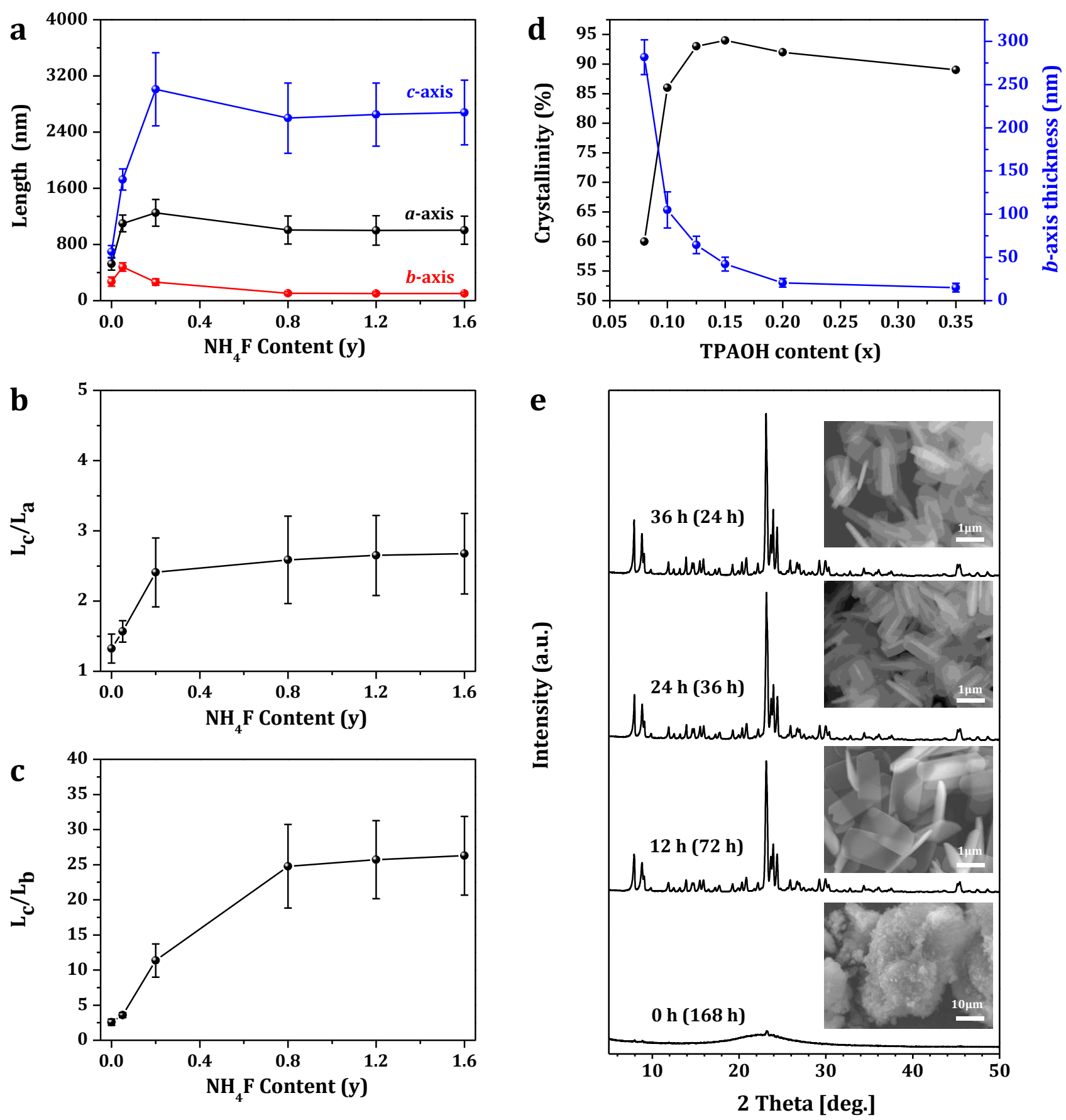

Figure 2. Synthesis parameters relevant to the formation of plate-like MFI zeolite crystals from the synthesis system x TPAOH: $1.0 \mathrm{SiO}_{2}$ : y $\mathrm{NH}_{4} \mathrm{~F}: 30 \mathrm{H}_{2} \mathrm{O}$ crystallized at $90^{\circ} \mathrm{C}$ : (a) the length along the three axes; (b) $\mathrm{L}_{\mathrm{c}} / \mathrm{L}_{\mathrm{a}}$ and (c) $\mathrm{L}_{\mathrm{c}} / \mathrm{L}_{\mathrm{b}}$ aspect ratios; (d) effects of TPAOH content on the relative crystallinity and $b$-axis thickness of MFI zeolite; (e) XRD patterns of solid products subjected to $0 \mathrm{~h}, 12$ $\mathrm{h}, 24 \mathrm{~h}$, and $36 \mathrm{~h}$ aging time (the crystallization time is shown in parentheses) from the system with $\mathrm{x}=$ $0.1, y=0.8$. Inset $(e)$ : representative SEM images of solid products. 


\section{Mechanism of plate-like MFI crystals formation}

The mechanistic analysis of plate-like MFI formation was performed using an all-silica system with molar composition 0.1 TPAOH: $1.0 \mathrm{SiO}_{2}: 0.8 \mathrm{NH}_{4} \mathrm{~F}: 30 \mathrm{H}_{2} \mathrm{O}$. The intermediates formed in the course of zeolite synthesis were studied to shed light on the process. As pointed out above, the gel was aged at $90{ }^{\circ} \mathrm{C}$ for $12 \mathrm{~h}$, then dissolved $\mathrm{NH}_{4} \mathrm{~F}$ was added, and the resultant mixture stirred at $90^{\circ} \mathrm{C}$ for $12 \mathrm{~h}$ more. Finally, the synthesis was performed under static conditions at $90{ }^{\circ} \mathrm{C}$ for $48 \mathrm{~h}$, as a sample was taken after $3,6,9,12,16,24,36$, and $48 \mathrm{~h}$.

The XRD pattern of the $12 \mathrm{~h}$ aged gel showed that it is amorphous (Figure S10). After the addition of $\mathrm{NH}_{4} \mathrm{~F}$, the first MFI trace, indicated by the characteristic diffraction line at $23.1^{\circ}$ Two Theta, appeared after $3 \mathrm{~h}$ crystallization. The crystalline phase developed rapidly, and a highly crystalline material was obtained after $48 \mathrm{~h}$ synthesis. Meanwhile, the amorphous phase gradually decreased and fully disappeared after $48 \mathrm{~h}$ crystallization (Figure S12).

The obtained intermediates, as well as the $12 \mathrm{~h}$ aged precursor, were inspected by transmission electron microscopy. After $3 \mathrm{~h}$ aging, only bulk, uniform in texture gel particles were observed (Figure S13). No substantial changes in the gel structure were found after $12 \mathrm{~h}$ aging (Figure $3 \mathrm{a}$ ). Upon the addition of $\mathrm{NH}_{4} \mathrm{~F}$ and $3 \mathrm{~h}$ hydrothermal treatment at $90{ }^{\circ} \mathrm{C}$, the gel precursor structure changed dramatically. Bulk gel disintegrated, and small nanometric particles appeared in the system. We attribute this effect to the fluorine ions' mineralizing ability, which breaks the gel structure and reorganizes silica species. Small, 10-20 nm in size isometric particles with oval shape was the only phase observed in the

product (Figure S14). The formation of nanoparticles certainly changes the exchange between the solid and liquid phase and contributes to the reaction kinetics in general. We anticipate the structure/chemistry of newly formed upon the fluorine addition nanoparticles contributes to the formation plate-like zeolite crystals. However, we do not have experimental prove supporting our suggestion. These tiny nanoparticles continue existing up to $12 \mathrm{~h}$ hydrothermal treatment. However, some changes in their textural organization occur. Namely, the particles agglomerate and built agglomerates with an elongated shape. The individual 10-20 nm nanoparticles are still well distinguishable in the aggregates (Figure 3b). Plate-like particles appear in the solid after $12 \mathrm{~h}$ treatment at $90{ }^{\circ} \mathrm{C}$ (Figure $3 \mathrm{c}$ ). According to the XRD study, the solid is still amorphous at this stage (Figure S11). Upon autoclave treatment, the number of 
plate-like particles increases, and they evolve into plate-like crystals with the MFI-type morphology. The first XRD trace of MFI-type material is detected after $3 \mathrm{~h}$ hydrothermal treatment in the autoclave (Figure S12). With the crystallization time extension, the amount of crystals increases at the expense of the isometric 10-20 nm particles (Figure 3d-f). These data show that the small colloid species with oval shape, observed at the beginning of the crystallization process, serve as nutrients for the crystal growth process. In the last stages of crystals growth $(24-48 \mathrm{~h})$, substantial growth of zeolite crystals is observed (Figure 3g-i). At this later stage, there is almost no amorphous phase in the system. Therefore, the growth is a consequence of the Ostwald ripening of the crystals, which does not change crystal morphology. Thus plate-like with very high $\mathrm{L}_{\mathrm{c}} / \mathrm{L}_{\mathrm{b}}$ aspect ratio MFI crystals are obtained (Figure $3 \mathrm{i}$ ).

The combined XRD-TEM investigation revealed that the addition of $\mathrm{NH}_{4} \mathrm{~F}$ and the treatment at $90{ }^{\circ} \mathrm{C}$ changed the gel structure substantially. Our interpretation is that the fluoride species break the gel structure, and thus, very small nanoparticles are formed, which form larger agglomerates. First zeolite crystallites are formed during this stage, most probably by the oriented aggregation of precursors particles. ${ }^{50}$ We do not have molecular level information of the mechanism leading to the formation of extra-thin MFI-type crystals and the preferential growth along $a$ - and $c$-axis leading to the well-developed (010) face. However, we clearly identify the formation of first crystallites during the $90{ }^{\circ} \mathrm{C}$ aging prior to the autoclave treatment, as indicated by the splitting of the pentasil vibration at $540 \sim 570 \mathrm{~cm}^{-1}$ in the FTIR spectra (Figure S4). ${ }^{51}$ The autoclave treatment just accelerates the growth rate without altering the growth mechanism. Thus, the particular morphology is a result of the preliminary $90{ }^{\circ} \mathrm{C}$ aging of the gel in the presence of $\mathrm{NH}_{4} \mathrm{~F}$. On the ground of collected results, the system's evolution leading to plate-like MFI crystals is presented in Scheme 1. 

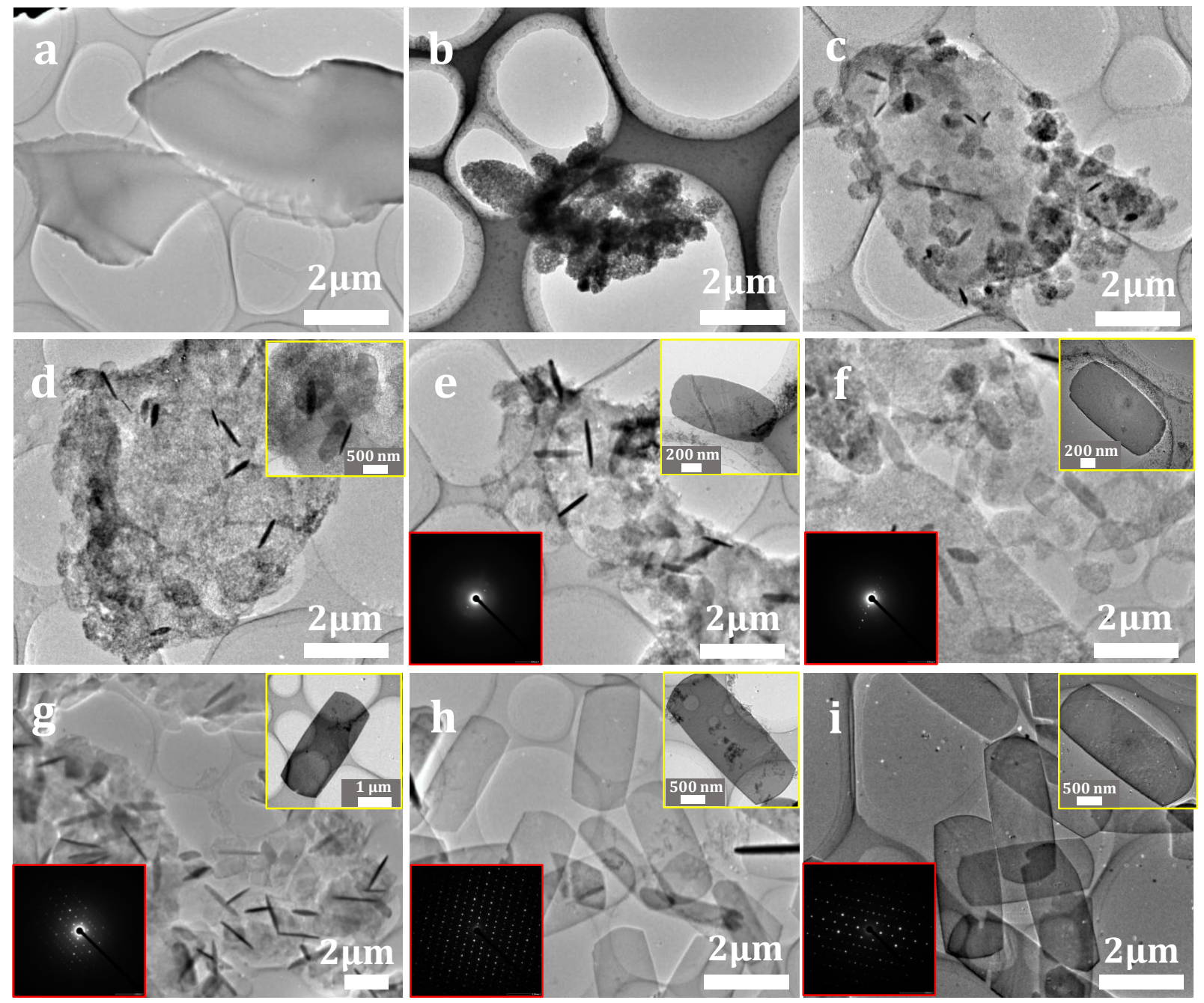

Figure 3. TEM analyses of products at different stages of zeolite synthesis: (a) After aging for $12 \mathrm{~h}$ at $90{ }^{\circ} \mathrm{C}$. After the addition of $\mathrm{NH}_{4} \mathrm{~F}$ and stirring at $90{ }^{\circ} \mathrm{C}$ for 6 (b) and $12 \mathrm{~h}$ (c). After hydrothermal treatment in the autoclave for 6 (d), 9 (e), 12 (f), 24 (g), 36 (h) and $48 \mathrm{~h}$ (i). Scale bar: $2 \mu \mathrm{m}$. Insets: views of single plate-like MFI zeolite crystal (marked with yellow) and the selected area electron diffraction patterns (marked with red). 


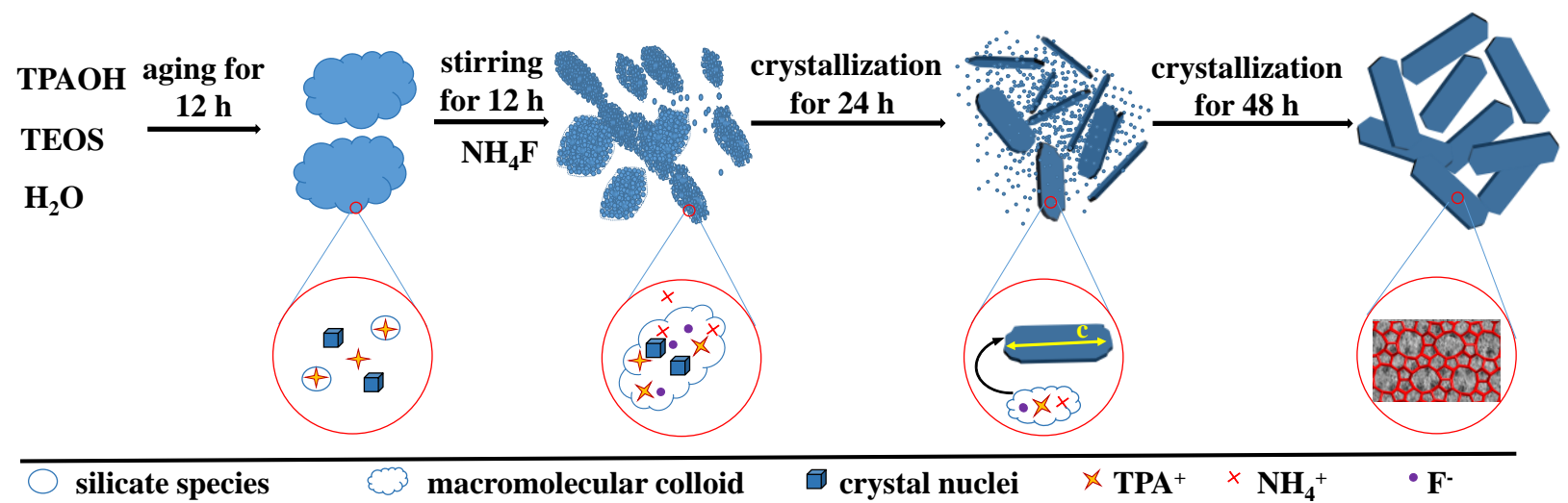

Scheme 1. Schematic presentation of different crystallization stages in the $\mathrm{NH}_{4} \mathrm{~F}$-containing system yielding plate-like MFI crystals.

Additional experiments were conducted to reveal the role of $\mathrm{NH}_{4} \mathrm{~F}$ in the formation of plate-like MFI crystals. $\mathrm{NaF}$ and $\mathrm{KF}$ were used as fluoride sources to replace $\mathrm{NH}_{4} \mathrm{~F}$. The use of both fluoride sources resulted in the formation of oval shape $90^{\circ}$ twins with a size of about $1 \mu \mathrm{m}$ (Figure S15). Since the fluoride content in the systems is similar, the observed effect raises the question about $\mathrm{NH}_{4}{ }^{+}$cation role. Sodium and potassium exhibit a structure-directing effect, and many zeolites are synthesized solely using these two alkali metals. In contrast, ammonium itself cannot generate a zeolite type material due to the weak charge and, consequently, limited interactions with the negatively charged silica species. Hence, we consider ammonium itself does not play an essential role in the growing process and thus does not disturb the formation of plate-like crystallites. Meanwhile, the $\mathrm{NH}_{4} \mathrm{~F}$ is a buffer that controls the $\mathrm{pH}$. After its addition, the $\mathrm{pH}$ of the gel changed from $\sim 12.3$ to $\sim 8.5$. The introduction of similar molar contents of $\mathrm{NaF}$ or $\mathrm{KF}$, adjust the $\mathrm{pH}$ value to $\sim 9.7$ and $\sim 10.1$, respectively. The great decrease of $\mathrm{pH}$ value from $\sim 12.3$ to $\sim 8.5$ certainly decreases the solubility of silicate species, and thus macromolecular colloid species are generated. ${ }^{51,52}$ Therefore, the addition of $\mathrm{NH}_{4} \mathrm{~F}$ has two well-established effects on the initial gel: i) breaking the gel structure and generation of nanoparticles that play an important role in forming plate-like crystals; and ii) decreasing the $\mathrm{pH}$ and thus changing the solubility of the silica species. The consequence of these two effects is the preferred growth in $a$ and $c$-directions, owing to the face with the slowest growth rate is the largest,${ }^{53}$ leading to substantial development of the (010) face. The ultimate result is the formation of ultra-thin crystals with a high aspect ratio between different crystal faces. It is worthy to note that the $\mathrm{F}^{-}$is vital for promoting the 
crystallization of MFI zeolite crystals. In a similar synthesis system, where the $\mathrm{NH}_{4} \mathrm{Cl}$ replaced $\mathrm{NH}_{4} \mathrm{~F}$, only an amorphous product was obtained after two weeks of crystallization (Figure S16).

Silicalite-1 synthesized, according to the present procedure in a mixed $\mathrm{OH}^{-} / \mathrm{F}^{-}$medium was compared with the counterparts synthesized in $\mathrm{OH}^{-}$and $\mathrm{F}^{-}$medium by means of solid-state NMR. The comparative study was based on ${ }^{29} \mathrm{Si}$ MAS, ${ }^{29} \mathrm{Si}\left\{{ }^{1} \mathrm{H}\right\}$ CPMAS NMR, ${ }^{29} \mathrm{Si}\left\{{ }^{19} \mathrm{~F}\right\}$ CPMAS NMR, and ${ }^{19} \mathrm{~F}$ MAS NMR analyses. All the samples display resonances in the $[-107 \mathrm{ppm} ;-120 \mathrm{ppm}]$ region corresponding to $\mathrm{Q}^{4}$ species. However, the sample synthesized in pure $\mathrm{F}^{-}$medium (Figure S17a3) shows well-resolved peaks corresponding to $\mathrm{Q}^{4}\left(\mathrm{Si}(\mathrm{OSi})_{4}\right)$ silicon species, reflecting different crystallographic $\mathrm{T}$ positions in MFI-structure. The $\mathrm{Q}^{4}$ resonances in samples synthesized in a mixed $\mathrm{OH}^{-} / \mathrm{F}^{-}$(Figure S17a1) and $\mathrm{OH}^{-}$ (Figure S17a2) media are broader because of a less ordered three-dimensional $\mathrm{Si}(\mathrm{OSi})_{4}$ network. This effect is due to local disordering, with a distribution of $\mathrm{Si}-\mathrm{O}-\mathrm{Si}$ angle and distance for each crystallographic silicon $\mathrm{T}$ site, leading to a broadening of the well-resolved peaks observed for a high-ordered 3d-network. ${ }^{54,55}$ It is even more obvious in the case of $\mathrm{OH}^{-}$medium synthesized silicalite-1 (Figure S17a2), where almost no discontinuity of the spectral line is observed. In addition, a broad resonance at $-103 \mathrm{ppm}$ corresponding to $\mathrm{Q}^{3}\left(\mathrm{Si}(\mathrm{OSi})_{3} \mathrm{OH}\right)$ is recorded for the silicalite-1 synthesized in mixed $\left(\mathrm{OH}^{-} / \mathrm{F}^{-}\right)$(Figure S17a1 and S17b1) and pure $\mathrm{OH}^{-}$medium (Figure S17a2 and S17b2). This resonance is a consequence of discontinuity between $\mathrm{SiO}_{4}$ tetrahedron of the zeolite framework, leading to the formation of $\mathrm{Si}-\mathrm{OH}$ bonds, and thus defects $\mathrm{Q}^{3}$. Nevertheless, the fitting of ${ }^{29} \mathrm{Si}$ MAS spectra pointed out a higher amount of defects for silicalite-1 synthesized in $\mathrm{OH}^{-}$medium $(25 \%)$ than for silicalite-1 synthesized in mixed medium $(8 \%)$. No $Q^{3}$ species are observed in the case of the sample synthesized in $\mathrm{NH}_{4} \mathrm{~F}$ medium (Figure S17a3), confirmed by no $\mathrm{Q}^{3}$ signals enhancement in the ${ }^{29} \mathrm{Si}\left\{{ }^{1} \mathrm{H}\right\}$ CPMAS spectrum (Figure S17b3), indicating a lack of Si-OH defects for this sample and reinforcing the idea of a well-ordered 3d-structure.

Furthermore, a broad peak appears at $-125 \mathrm{ppm}$ for the silicalite-1 sample synthesized in $\mathrm{F}^{-}$medium, which is not observed for the pure $\mathrm{OH}^{-}$medium synthesized counterpart. This peak is attributed to the fluoride ions, which have certain mobility between $\mathrm{SiO}_{4 / 2}$ tetrahedron. The large signal is typical of framework silicon sites that undergo dynamic exchange between 4- and 5-coordinated environments due to fluoride ion mobility. ${ }^{56}$ This signal is not observed in the sample synthesized in mixed $\left(\mathrm{OH}^{-} / \mathrm{F}^{-}\right)$ 
medium (Figure S17a1 and S17b1). However, this broad resonance at $-125 \mathrm{ppm}$ appears and is enhanced by ${ }^{29} \mathrm{Si}\left\{{ }^{19} \mathrm{~F}\right\} \mathrm{CP}$ transfer (Figure $\mathrm{S} 17 \mathrm{c} 1$ ), suggesting the mobility of $\mathrm{F}^{-}$ions between $\mathrm{SiO}_{4 / 2}$ tetrahedron. The resonances at -109 and $-117 \mathrm{ppm}$ are also broadened slightly by ${ }^{29} \mathrm{Si}\left\{{ }^{19} \mathrm{~F}\right\} \mathrm{CP}$ process, pointing out that these silicon sites are affected by a disordering of silicon atoms at the vicinity of $\mathrm{F}^{-}$, or an influence of the mobility of the $\mathrm{F}^{-}$ion but to a lesser degree. Furthermore, the resonance attributed to $\mathrm{Q}^{3}$ defects disappears in ${ }^{29} \mathrm{Si}\left\{{ }^{19} \mathrm{~F}\right\}$ CPMAS spectrum, in agreement with this assignment.

Figure S18 shows the ${ }^{19} \mathrm{~F}$ MAS NMR spectra of silicalite- 1 synthesized in $\mathrm{NH}_{4} \mathrm{~F}$ and mixed $\left(\mathrm{OH}^{-} / \mathrm{F}^{-}\right)$ medium (Figure S18a and S18b). The spectrum area in the dotted line is emphasized in the inset. Both spectra exhibit two isotropic signals at $-79 \mathrm{ppm}$ and $-64 \mathrm{ppm}$ (with a higher intensity for the latter), indicating two environments for fluoride ions. Fits of these spectra show integrated intensities of $99.5 \%$ and $89 \%$ for the main signal for silicalite- 1 synthesized in $\mathrm{NH}_{4} \mathrm{~F}$ and mixed medium, respectively.

The signal at $-64 \mathrm{ppm}$ is typical of as-synthesized F-MFI. It is known to result from $\mathrm{F}^{-}$located in $\left[4^{1} 5^{2} 6^{2}\right]$ cavity types, where $\mathrm{F}^{-}$ions are subjected to a dynamic exchange between penta-coordinated $\mathrm{Si}$

sites $\left(\left[\mathrm{SiO}_{4 / 2} \mathrm{~F}\right]^{-}\right) .{ }^{56-58}$ The second site at $-79 \mathrm{ppm}$ can be due to the SDA $\left(\mathrm{TPA}^{+}\right)$in the straight channels, encountering $\mathrm{F}^{-}$ions in the cavities. This signal is also attributed to fluorine close to defects. However, the last assignment is in disagreement with the fact that the fluoride medium synthesized silicalite-1 does not contain framework defects, as illustrated in Figure $\mathrm{S} 17 \mathrm{~b} 3\left({ }^{29} \mathrm{Si}\left\{{ }^{1} \mathrm{H}\right\}\right.$ CPMAS spectrum). Thus, the most plausible interpretation of these two signals would be that there exist two ${ }^{19} \mathrm{~F}$ environments, resulting from different interactions of $\left[\mathrm{SiO}_{4 / 2} \mathrm{~F}\right]^{-}$with the $\mathrm{TPA}^{+}$branches with different conformations in straight and sinusoidal channels. ${ }^{59}$ This assignment is also in agreement with other existing studies. $^{57,60}$

\section{Large-scale synthesis of plate-like MFI zeolite}

Upscaling synthesis is a challenging and often difficult exercise. A number of parameters are changed when upscale from laboratory to semi-industrial or large scale vessels. For instance, the contact surface between gel and autoclave, heat transfer, concentration gradients, vapor disengagement, and reagent grade. ${ }^{61}$ Thus, there exists a large gap between the laboratory-scale synthesis and their industrial implication. Consequently, scale-up is a key problem in zeolite production, which greatly limits the 
industrial application of zeolites with various topologies.

The ultra-thin plate-like silicalite-1 can be easily synthesized at low temperature and under ambient pressure, the conditions gracefully suitable to large-scale synthesis. The applicability of our approach to a large scale synthesis was verified by using a $20 \mathrm{~L}$ open glass reactor (Figure 4a). The transparent glass reactor allows monitoring the physical changes in the synthesis system, as shown in Figure $4 \mathrm{~b}$. Also, the crystallization process in the employed open synthesis system can be easily monitored by sampling at different times. The scale-up experiment was successful, and $\sim 1320 \mathrm{~g}$ dry zeolite powder was obtained (Figure 4c, after calcination). The product yield is calculated to be $\sim 97 \%$ based on silica conversion, which is impressively high for the large-scale zeolite synthesis. The XRD patterns (Figure 4d) and SEM images (Figure 4e) revealed that the crystallization in the 20 L glass reactor was completed within $96 \mathrm{~h}$, noticeable longer than that in the $20 \mathrm{~mL}$ autoclave. This was the only negative effect of the scaled-up synthesis, which we attribute to the slightly lower temperature employed $\left(88 \pm 2\right.$ versus $\left.90{ }^{\circ} \mathrm{C}\right)$ and a slower rise of the temperature in the larger vessel. Nevertheless, the quality of the final product was just as good as the counterpart obtained with laboratory equipment (Figure 1 and 4). The result of scaled-up synthesis clearly indicates that the synthesis strategy developed in this work is readily applicable to industrial scale. 


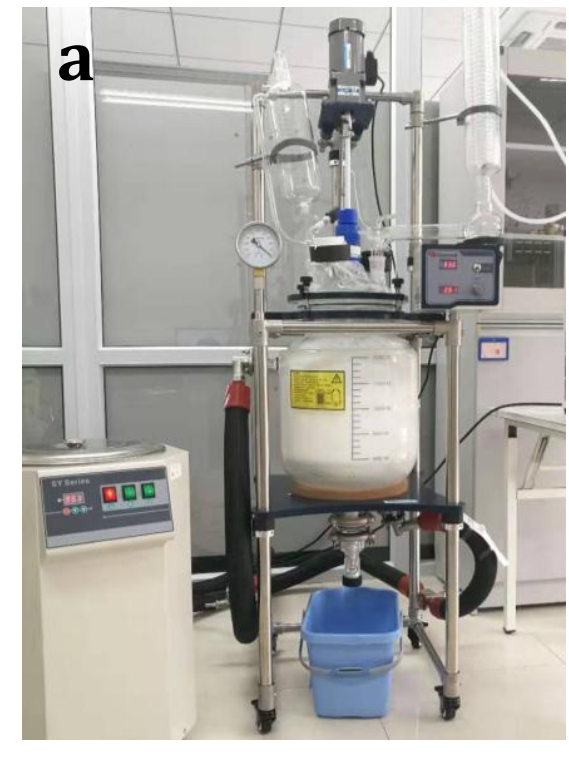

d

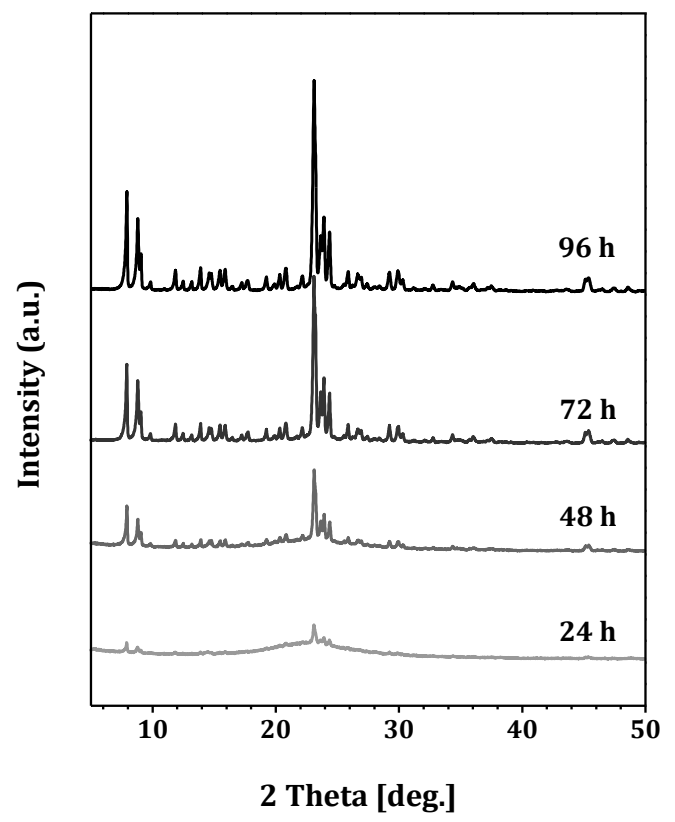

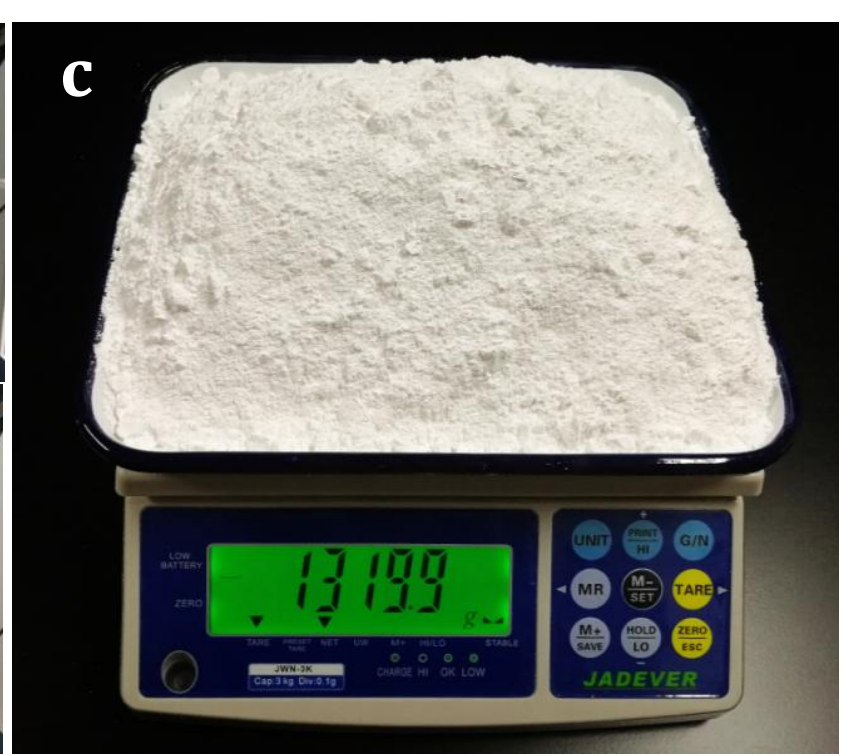

e
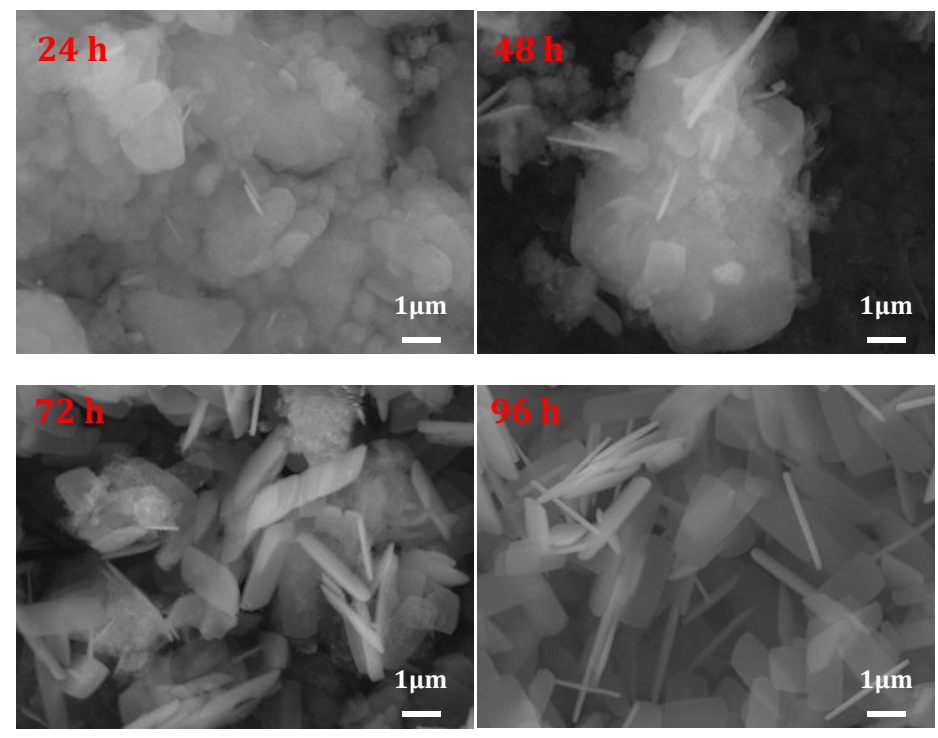

Figure 4. Large-scale syntheses of plate-like MFI zeolite from a gel with composition: 0.1 TPAOH: 1.0 $\mathrm{SiO}_{2}: 0.8 \mathrm{NH}_{4} \mathrm{~F}: 30 \mathrm{H}_{2} \mathrm{O} ; \mathrm{T}=88 \pm 2{ }^{\circ} \mathrm{C}$, crystallization time $96 \mathrm{~h}$. (a) Picture of a $20 \mathrm{~L}$ glass reactor for large-scale synthesis; (b) Visualization of synthesis process from the initial synthesis gel (upper level) to crystallized product (lower level); (c) Silicalite-1 product after calcination; (d) XRD patterns of solid products obtained after different synthesis time; (e) SEM images of solid products obtained after different synthesis time. 
The catalytic applications of zeolites require the presence of active sites. In this section, we report the synthesis of Al-MFI (ZSM-5) and Ga-MFI counterparts of silicalite-1. The procedure used for the synthesis of plate-like silicalite-1 was employed as a heteroatom was introduced in the initial gel (see Supporting Information for details). Thus a gel with $\mathrm{Si} / \mathrm{Al}$ ratio 50 was prepared and subjected to hydrothermal treatment at $90{ }^{\circ} \mathrm{C}$. All obtained materials were highly crystalline. The initial gel with Si/Al ratio of 50 yielded crystalline ZSM-5 crystals with Si/Al of 72 (Table S1). The framework Al content did not increase even when an initial gel with $\mathrm{Si} / \mathrm{Al}$ ratio of 25 was employed. This result pointed out a threshold of the framework $\mathrm{Al}$ incorporation under our synthesis conditions. The most plausible reasons limiting the $\mathrm{Al}$ incorporation in the ZSM-5 crystals are: i) the presence of $\mathrm{F}^{-}$ions that compensate the positively charged $\mathrm{TPA}^{+}$; ii) the absence of alkali cations; and iii) the low synthesis temperature. The synthesized ZSM-5 contained, namely, tetrahedral Al as shown by the dominant resonance at $55 \mathrm{ppm}$ in the ${ }^{27} \mathrm{Al}$ MAS NMR spectrum (Figure S19). The as-obtained plate-like ZSM-5 has similar physicochemical characteristics with the industrial ZSM-5 nanocrystalline sample (Figure S20 and Table S1). Compared with plate-like silicalite-1 crystals, the ZSM-5 counterpart exhibits similar morphology and textural properties (Figure 1c, 5a, S21 and Table S1).

Ga-MFI counterpart of silicalite-1 was also successfully obtained (Figure S22). The materials showed $\mathrm{Si} / \mathrm{Ga}$ ratio close to $100(\mathrm{Si} / \mathrm{Ga}=98)$, high crystallinity, and pore volume similar to silicalite-1 synthesized under the same conditions (Table S1). The crystals still exhibited plate-like morphology (Figure S23 and S24), however, compared to the crystals of silicalite-1, smaller crystals with increased thickness along the $b$-axis can be observed. The aspect ratio of $\mathrm{L}_{\mathrm{c}} / \mathrm{L}_{\mathrm{b}}$ for Ga-MFI was $\sim 10$, which is much lower than silicalite-1 synthesized under the same conditions.

\section{Catalytic performance of plate-like ZSM-5 in the MTH reaction}

Methanol-to-hydrocarbons (MTH) is often used as a important model reaction for exploring the improved diffusion behaviors of morphology-controlled zeolite catalysts. ${ }^{62,63}$ Herein, the catalytic performance of plate-like HZSM-5 crystals, in comparison with commercial ZSM-5 nanocrystals with a similar number of Brønsted acid sites (Table S1), was evaluated in the MTH reaction. As shown in Figure 5b, plate-like HZSM-5 samples exhibit an ultra-long lifetime of $250 \mathrm{~h}$ (methanol 
conversion >99\%), which is five times longer than that of commercial ZSM-5 nanocrystals under identical reaction conditions. The extended lifetime is attributed to the shorter diffusion path along the straight channel of ZSM-5 crystals. The plate-like crystals of thickness around $100 \mathrm{~nm}$ improve the mass transfer significantly and slow down the coke accumulation. According to the time-dependent product distribution in MTH reaction (Figure 5c-d), higher propylene selectivity ( 30\% versus $\sim 26 \%$ ) but lower BTX selectivity ( 14\% versus $\sim 17 \%)$ was obtained on plate-like ZSM-5 samples in comparison with commercial ZSM-5 nanocrystals, as a result of the diffusion control. Therefore, the plate-like HZSM-5 is a high performing acid catalyst for the industrial MTH reaction, and it also holds promises for other catalytic applications, especially when dealing with bulky molecules. ${ }^{8}$
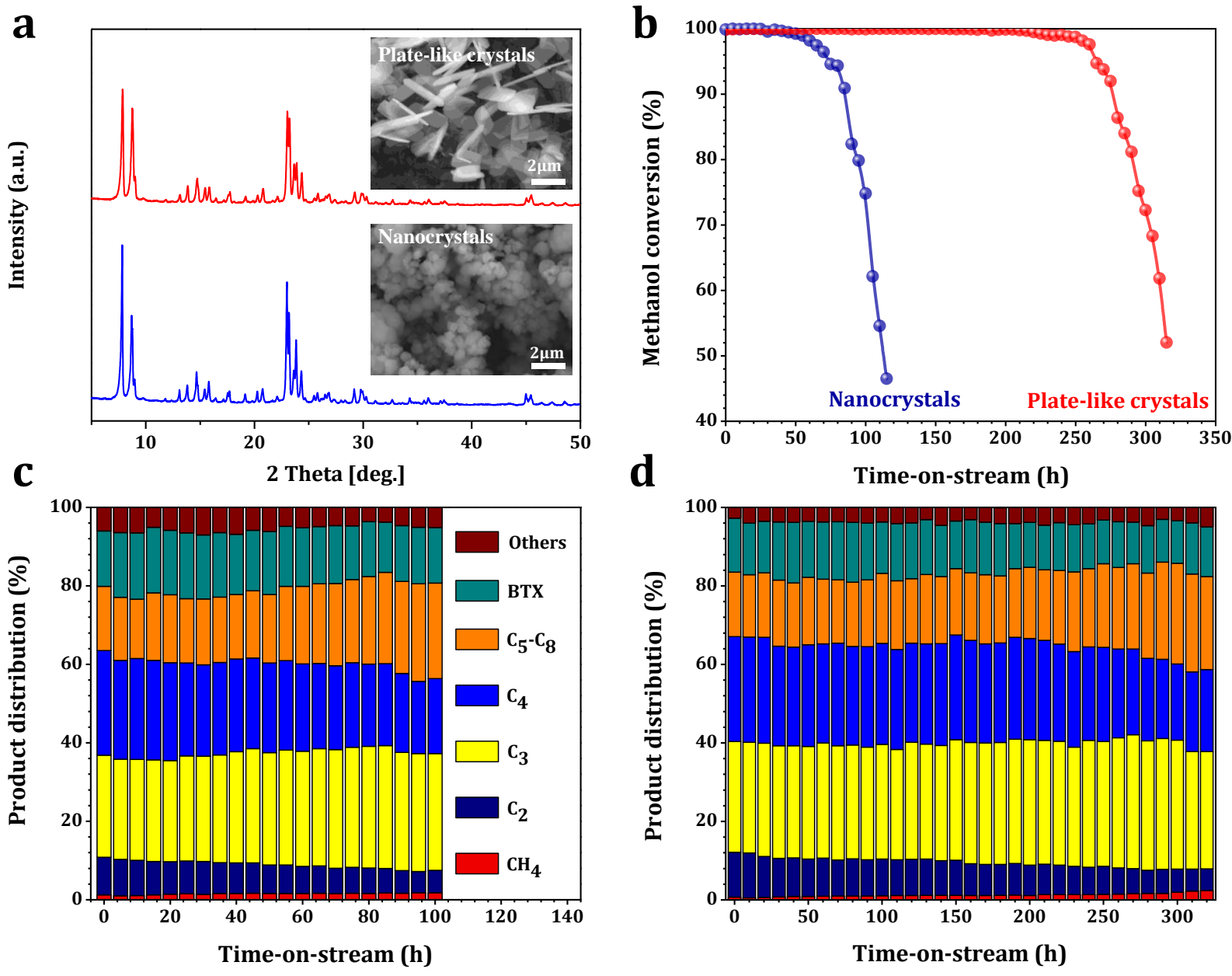

Figure 5. Comparative study of the MTH performance of plate-like HZSM-5 crystals and commercial ZSM-5 nanocrystals: (a) XRD patterns of calcined plate-like HZSM-5 (top, $\mathrm{Si} / \mathrm{Al}=72$ ) and commercial ZSM-5 nanocrystals (bottom, Si/Al = 74); Inset: representative SEM images of solid products; (b) Methanol conversion as a function of reaction time over two different ZSM-5 samples; Product 
selectivity as a function of time over commercial ZSM-5 nanocrystals (c) and plate-like HZSM-5 (d) in MTH reaction. Reaction conditions: $0.4 \mathrm{~g}$ catalyst, WHSV $=2 \mathrm{~h}^{-1}, \mathrm{~T}=425^{\circ} \mathrm{C}$, ambient pressure.

\section{Conclusions}

A synthetic approach yielding ultra-thin plate-like MFI-type crystals without using special structure-directing reagents or organic growth-modifiers is developed. The crystal thickness along the straight channel ( $b$-axis) can be effectively tuned to several tens of $\mathrm{nm}$, thus shortening the diffusion path. This simple approach also allows tuning the aspect ratio between different crystal faces, thus developing the crystal face with the channel system of interest. Consequently, the number of pore openings per unit crystal surface is maximized, and the diffusion limitations' impact is minimized.

The synthetic approach combines preliminary aging in F-free medium with a fluoride-assisted low-temperature crystallization process. Thus the nucleation process is split from the crystallization, which takes place in F-containing medium. A suitable aging time $(12 \mathrm{~h})$ is indispensable for the formation of viable MFI nuclei, while the crystallization is controlled by the presence of fluorine mineralizer. The specific effect of $\mathrm{F}^{-}$on the precursor gel structure, the $\mathrm{pH}$ of the gel, and thus the solubility of the silica species, resulting in an alteration of the growing mechanism, leads to the formation of ultra-thin crystals with high $\mathrm{L}_{\mathrm{c}} / \mathrm{L}_{\mathrm{b}}$ aspect ratio.

The above-described synthesis strategy is versatile, efficient, and applicable for the industrial production of plate-like zeolites. We have obtained a similar result, i.e., ultra-thin plate-like FER-type zeolite (Figure S25), which proves that a general strategy applicable to different zeolite types is developed. It can be scaled up for the synthesis of kilogram-scale siliceous MFI zeolites in an open glass reactor with an extremely high yield of $\sim 97 \%$, and it can also be extended to the synthesis of heteroatom containing MFI zeolites like Al-MFI and Ga-MFI.

\section{Associated content}

\section{Supporting information}

The supporting information is available for this paper, including Materials and Methods, Figures S1-S25 and Table S1. 


\section{Author information}

\section{Corresponding Author:}

*E-mail: wuguangjun@nankai.edu.cn (G.W.);

*E-mail: valentin.valtchev@ensicaen.fr (V.V.).

\section{ORCID :}

Valentin Valtchev: 0000-0002-2341-6397

\section{Notes}

The authors declare no competing financial interests.

\section{Acknowledgments}

We acknowledge the National Natural Science Funds of China (21722303, 22025203), the Municipal Natural Science Funds of Tianjin (18JCJQJC47400), 111 Project (B18030), and the China Scholarship Council for supporting the work. V.V. acknowledges the financial support from the Industrial Chair ANR-TOTAL “NanoClean Energy” (ANR-17-CHIN-0005-01) and FEDER 18P01675.

\section{References}

(1) Barrer, R. M. Hydrothermal Chemistry of Zeolites; London, 1982.

(2) Milton, R. M. Molecular Sieve Science and Technology, A Historical Perspective; Washington, DC,1989.

(3) Breck, D. W. Zeolite Molecular Sieves: Structure, Chemistry and Use, Wiley: New York, 1974.

(4) Na, K.; Choi, M.; Ryoo, R. Recent Advances in the Synthesis of Hierarchically Nanoporous Zeolites. Micropor. Mesopor. Mater. 2013, 166, 3-19.

(5) Hartmann, M.; Machoke, A. G.; Schwieger, W. Catalytic Test Reactions for the Evaluation of Hierarchical Zeolites. Chem. Soc. Rev. 2016, 45, 3313-3330. 
(6) Wei, Y.; Parmentier, T. E.; De Jong, K. P.; Zečević, J. Tailoring and Visualizing the Pore Architecture of Hierarchical Zeolites. Chem. Soc. Rev. 2015, 44, 7234-7261.

(7) Guisnet, M.; Ribeiro, F. R. Deactivation and Regeneration of Solid Catalysts; Imperial College Press, London, 2011.

(8) Choi, M.; Na, K.; Kim, J.; Sakamoto, Y.; Terasaki, O.; Ryoo, R. Stable Single-Unit-Cell Nanosheets of Zeolite MFI as Active and Long-Lived Catalysts. Nature 2009, 461, 246-249.

(9) Valtchev, V.; Tosheva, L. Porous Nanosized Particles : Preparation, Properties, and Applications. Chem. Rev. 2013, 113, 6734-6760.

(10) Mintova, S.; Jaber, M.; Valtchev, V. Nanosized Microporous Crystals: Emerging Applications. Chem. Soc. Rev. 2015, 44, 7207-7233.

(11) Mintova, S.; Gilson, J. P.; Valtchev, V. Advances in Nanosized Zeolites. Nanoscale 2013, 5, 6693-6703.

(12) Tosheva, L.; Valtchev, V. P. Nanozeolites: Synthesis, Crystallization Mechanism, and Applications. Chem. Mater. 2005, 17, 2494-2513.

(13) Möller, K.; Bein, T. Mesoporosity - a New Dimension for Zeolites. Chem. Soc. Rev. 2013, 42, $3689-3707$

(14) Serrano, D. P.; Escola, J. M.; Pizarro, P. Synthesis Strategies in the Search for Hierarchical Zeolites. Chem. Soc. Rev. 2013, 42, 4004-4035.

(15) Tao, Y.; Kanoh, H.; Abrams, L.; Kaneko, K. Mesopore-Modified Zeolites : Preparation, Characterization, and Applications. Chem. Rev. 2006, 106, 896-910.

(16) Holm, M. S.; Taarning, E.; Egeblad, K.; Christensen, C. H. Catalysis with Hierarchical Zeolites. Catal. Today 2011, 168, 3-16.

(17) Meng, L.; Zhu, X.; Mezari, B.; Pestman, R.; Wannapakdee, W.; Hensen, E. J. M. On the Role of Acidity in Bulk and Nanosheet [T]MFI $\left(\mathrm{T}=\mathrm{Al}^{3+}, \mathrm{Ga}^{3+}, \mathrm{Fe}^{3+}, \mathrm{B}^{3+}\right)$ Zeolites in the Methanol-to-Hydrocarbons Reaction. ChemCatChem 2017, 9, 3942-3954.

(18) Liu, Y.; Qiang, W.; Ji, T.; Zhang, M.; Li, M.; Lu, J.; Liu, Y. Uniform Hierarchical MFI Nanosheets Prepared via Anisotropic Etching for Solution-Based Sub-100-nm Thick Oriented MFI Layer Fabrication. Sci. Adv. 2020, 6, 1-9. 
(19) Xiao, X.; Zhang, Y.; Jiang, G.; Liu, J.; Han, S.; Zhao, Z.; Wang, R.; Li, C.; Xu, C.; Duan, A.; Wang, Y.; Liu, J.; Wei, Y. Simultaneous Realization of High Catalytic Activity and Stability for Catalytic Cracking of: N -Heptane on Highly Exposed (010) Crystal Planes of Nanosheet ZSM-5 Zeolite. Chem. Commun. 2016, 52, 10068-10071.

(20) Jeon, M. Y.; Kim, D.; Kumar, P.; Lee, P. S.; Rangnekar, N.; Bai, P.; Shete, M.; Elyassi, B.; Lee, H. S.; Narasimharao, K.; Basahel, S. N.; Al-Thabaiti, S.; Xu, W.; Cho, H. J.; Fetisov, E. O.; Thyagarajan, R.; Dejaco, R. F.; Fan, W.; Mkhoyan, K. A.; Siepmann, J. I.; Tsapatsis, M. Ultra-Selective High-Flux Membranes from Directly Synthesized Zeolite Nanosheets. Nature 2017, 543, 690-694.

(21) Hu, S.; Shan, J.; Zhang, Q.; Wang, Y.; Liu, Y.; Gong, Y.; Wu, Z.; Dou, T. Selective Formation of Propylene from Methanol over High-Silica Nanosheets of MFI Zeolite. Appl. Catal., A. 2012, $445-446,215-220$.

(22) Ji, Y.; Shi, B.; Yang, H.; Yan, W. Synthesis of Isomorphous MFI Nanosheet Zeolites for Supercritical Catalytic Cracking of n-Dodecane. Appl. Catal., A. 2017, 533, 90-98.

(23) Seo, Y.; Cho, K.; Jung, Y.; Ryoo, R. Characterization of the Surface Acidity of MFI Zeolite Nanosheets by ${ }^{31} \mathrm{P}$ NMR of Adsorbed Phosphine Oxides and Catalytic Cracking of Decalin. ACS Catal. 2013, 3, 713-720.

(24) Xu, M.; Mukarakate, C.; Iisa, K.; Budhi, S.; Menart, M.; Davidson, M.; Robichaud, D. J.; Nimlos, M. R.; Trewyn, B. G.; Richards, R. M. Deactivation of Multilayered MFI Nanosheet Zeolite during Upgrading of Biomass Pyrolysis Vapors. ACS Sustain. Chem. Eng. 2017, 5, 5477-5484.

(25) Kim, J.; Park, W.; Ryoo, R. Surfactant-Directed Zeolite Nanosheets: A High-Performance Catalyst for Gas-Phase Beckmann Rearrangement. ACS Catal. 2011, 1, 337-341.

(26) Kim, D.; Jeon, M. Y.; Stottrup, B. L.; Tsapatsis, M. Para-Xylene Ultra-Selective Zeolite MFI Membranes Fabricated from Nanosheet Monolayers at the Air-Water Interface. Angew. Chem. Int. Ed. 2018, 57, 480-485.

(27) Zhang, H.; Xiao, Q.; Guo, X.; Li, N.; Kumar, P.; Rangnekar, N.; Jeon, M. Y.; Al-Thabaiti, S.; Narasimharao, K.; Basahel, S. N.; Topuz, B.; Onorato, F. J.; Macosko, C. W.; Mkhoyan, K. A.; Tsapatsis, M. Open-Pore Two-Dimensional MFI Zeolite Nanosheets for the Fabrication of 
Hydrocarbon-Isomer-Selective Membranes on Porous Polymer Supports. Angew. Chem. Int. Ed. 2016, 55, 7184-7187.

(28) Na, K.; Park, W.; Seo, Y.; Ryoo, R. Disordered Assembly of MFI Zeolite Nanosheets with a Large Volume of Intersheet Mesopores. Chem. Mater. 2011, 23, 1273-1279.

(29) Na, K.; Chol, M.; Park, W.; Sakamoto, Y.; Terasakl, O.; Ryoo, R. Pillared MFI Zeolite Nanosheets of a Single-Unit-Cell Thickness. J. Am. Chem. Soc. 2010, 132, 4169-4177.

(30) Shen, X.; Mao, W.; Ma, Y.; Xu, D.; Wu, P.; Terasaki, O.; Han, L.; Che, S. A Hierarchical MFI Zeolite with a Two- Dimensional Square Mesostructure. Angew. Chem. Int. Ed 2018, 57, 724-728.

(31) Maheshwari, S.; Jordan, E.; Kumar, S.; Bates, F. S.; Penn, R. L.; Shantz, D. F.; Tsapatsis, M. Layer Structure Preservation during Swelling, Pillaring, and Exfoliation of a Zeolite Precursor. J. Am. Chem. Soc. 2008, 130, 1507-1516.

(32) Itani, L.; Bozhilov, K. N.; Clet, G.; Delmotte, L.; Valtchev, V. Factors That Control Zeolite L Crystal Size. Chem. Eur. J. 2011, 17, 2199-2210.

(33) Larlus, O.; Valtchev, V. P. Crystal Morphology Control of LTL-Type Zeolite Crystals. Chem. Mater. 2004, 16, 3381-3389.

(34) Zhang, Q.; Mayoral, A.; Terasaki, O.; Zhang, Q.; Ma, B.; Zhao, C.; Yang, G.; Yu, J. Amino Acid-Assisted Construction of Single-Crystalline Hierarchical Nanozeolites via Oriented-Aggregation and Intraparticle Ripening. J. Am. Chem. Soc. 2019, 3772-3776.

(35) Larlus, O.; Valtchev, V. P. Control of the Morphology of All-Silica BEA-Type Zeolite Synthesized in Basic Media. Chem. Mater. 2005, 17, 881-886.

(36) Li, S.; Li, J.; Dong, M.; Fan, S.; Zhao, T.; Wang, J.; Fan, W. Strategies to Control Zeolite Particle Morphology. Chem. Soc. Rev. 2019, 48, 885-907.

(37) Zhang, Q.; Chen, G.; Wang, Y.; Chen, M.; Guo, G.; Shi, J.; Luo, J.; Yu, J. High-Quality Single-Crystalline MFI-Type Nanozeolites: A Facile Synthetic Strategy and MTP Catalytic Studies. Chem. Mater. 2018, 30, 2750-2758.

(38) Chen, X.; Yan, W.; Cao, X.; Yu, J.; Xu, R. Fabrication of Silicalite-1 Crystals with Tunable Aspect Ratios by Microwave-Assisted Solvothermal Synthesis. Micropor. Mesopor. Mater. 2009, 
$119,217-222$.

(39) Lupulescu, A. I.; Kumar, M.; Rimer, J. D. A Facile Strategy to Design Zeolite L Crystals with Tunable Morphology and Surface Architecture. J. Am. Chem. Soc. 2013, 135, 6608-6617.

(40) Lupulescu, A. I.; Rimer, J. D. Tailoring Silicalite-1 Crystal Morphology with Molecular Modifiers. Angew. Chem. Int. Ed. 2012, 51, 3345-3349.

(41) Li, H.; Liu, X.; Qi, S.; Xu, L.; Shi, G.; Ding, Y.; Yan, X.; Huang, Y.; Geng, J. Graphene Oxide Facilitates Solvent-Free Synthesis of Well-Dispersed, Faceted Zeolite Crystals. Angew. Chem. Int. Ed. 2017, 56, 14090-14095.

(42) Li, R.; Smolyakova, A.; Maayan, G.; Rimer, J. D. Designed Peptoids as Tunable Modifiers of Zeolite Crystallization. Chem. Mater. 2017, 29, 9536-9546.

(43) Qin, W.; Agarwal, A.; Choudhary, M. K.; Palmer, J. C.; Rimer, J. D. Molecular Modifiers Suppress Nonclassical Pathways of Zeolite Crystallization. Chem. Mater. 2019, 31, 3228-3238.

(44) Kessler, H.; Patarin, J.; Schott-Darie, C. The Opportunities of the Fluoride Route in the Synthesis of Microporous Materials; Stud. Surf. Sci. Catal. 1994; 85, 75-113.

(45) Caullet, P.; Paillaud, J. L.; Simon-Masseron, A.; Soulard, M.; Patarin, J. The Fluoride Route: A Strategy to Crystalline Porous Materials. C. R. Chim. 2005, 8, 245-266.

(46) Zhou, M.; Korelskiy, D.; Ye, P.; Grahn, M.; Hedlund, J. A Uniformly Oriented MFI Membrane for Improved $\mathrm{CO}_{2}$ Separation. Angew. Chem. Int. Ed. 2014, 53, 3492-3495.

(47) Pereira, M. M.; Gomes, E. S.; Silva, A. V.; Pinar, A. B.; Willinger, M. G.; Shanmugam, S.; Chizallet, C.; Laugel, G.; Losch, P.; Louis, B. Biomass-Mediated ZSM-5 Zeolite Synthesis: When Self-Assembly Allows to Cross the Si/Al Lower Limit. Chem. Sci. 2018, 9, 6532-6539.

(48) Kirschhock, C. E. A.; Ravishankar, R.; Verspeurt, F.; Grobet, P. J.; Jacobs, P. A.; Martens, J. A. Identification of Precursor Species in the Formation of MFI Zeolite in the TPAOH-TEOS- $\mathrm{H}_{2} \mathrm{O}$ System. J. Phys. Chem. B 1999, 103, 4965-4971.

(49) Li, Q.; Mihailova, B.; Creaser, D.; Sterte, J. Aging Effects on the Nucleation and Crystallization Kinetics of Colloidal TPA-Silicalite-1. Micropor. Mesopor. Mater. 2001, 43, 51-59.

(50) Grand, J.; Awala, H.; Mintova, S. Mechanism of Zeolites Crystal Growth: New Findings and Open Questions. CrystEngComm 2016, 18, 650-664. 
(51) Lesthaeghe, D.; Vansteenkiste, P.; Verstraelen, T.; Ghysels, A.; Kirschhock, C. E. A.; Martens, J. A.; Van Speybroeck, V.; Waroquier, M. MFI Fingerprint: How Pentasil-Induced IR Bands Shift during Zeolite Nanogrowth. J. Phys. Chem. C 2008, 112, 9186-9191.

(52) Fan, W.; Duan, R. G.; Yokoi, T.; Wu, P.; Kubota, Y.; Tatsumi, T. Synthesis, Crystallization Mechanism, and Catalytic Properties of Titanium-Rich TS-1 Free of Extraframework Titanium Species. J. Am. Chem. Soc. 2008, 130, 10150-10164.

(53) Sunagawa, I. Crystals: Growth, Morphology, and Perfection; Cambridge University Press, Cambridge, UK, 2005.

(54) Fyfe, C. A.; Grondey, H.; Feng, Y.; Kokotailo, G. T. Natural-Abundance Two-Dimensional ${ }^{29} \mathrm{Si}$ MAS NMR Investigation of the Three-Dimensional Bonding Connectivities in the Zeolite Catalyst ZSM-5. J. Am. Chem. Soc. 1990, 112, 8812-8820.

(55) Cadars, S.; Brouwer, D. H.; Chmelka, B. F. Probing Local Structures of Siliceous Zeolite Frameworks by Solid-State NMR and First-Principles Calculations of ${ }^{29} \mathrm{Si}-\mathrm{O}-{ }^{29} \mathrm{Si}$ Scalar Couplings. Phys. Chem. Chem. Phys. 2009, 11, 1825-1837.

(56) Koller, H.; Wölker, A.; Villaescusa, L. A.; Díaz-Cabañas, M. J.; Valencia, S.; Camblor, M. A. Five-Coordinate Silicon in High-Silica Zeolites. J. Am. Chem. Soc. 1999, 121, 3368-3376.

(57) Fyfe, C. A.; Brouwer, D. H.; Lewis, A. R.; Chézeau, J. M. Location of the Fluoride Ion in Tetrapropylammonium Fluoride Silicalite-1 Determined by ${ }^{1} \mathrm{H} /{ }^{19} \mathrm{~F} /{ }^{29} \mathrm{Si}$ Triple Resonance CP, REDOR, and TEDOR NMR Experiments. J. Am. Chem. Soc. 2001, 123, 6882-6891.

(58) Dib, E.; Gimenez, A.; Mineva, T.; Alonso, B. Preferential Orientations of Structure Directing Agents in Zeolites. Dalt. Trans. 2015, 44, 16680-16683.

(59) Rojas, A.; Gómez-Hortigüela, L.; Camblor, M. A. Zeolite Structure Direction by Simple Bis(Methylimidazolium) Cations: The Effect of the Spacer Length on Structure Direction and of the Imidazolium Ring Orientation on the ${ }^{19}$ F NMR Resonances. J. Am. Chem. Soc. 2012, 134, 3845-3856.

(60) Dib, E.; Mineva, T.; Gaveau, P.; Alonso, B. ${ }^{14} \mathrm{~N}$ Solid-State NMR: A Sensitive Probe of the Local Order in Zeolites. Phys. Chem. Chem. Phys. 2013, 15, 18349-18352.

(61) Hendershot, D. C.; Sarafin, A. Safe Chemical Reaction Scale Up. Chem. Heal. Saf. 2005, 12, 
$29-35$.

(62) Gallego, E. M.; Paris, C.; Díaz-Rey, M. R.; Martínez-Armero, M. E.; Martínez-Triguero, J.; Martínez, C.; Moliner, M.; Corma, A. Simple Organic Structure Directing Agents for Synthesizing Nanocrystalline Zeolites. Chem. Sci. 2017, 8, 8138-8149.

(63) Dai, H.; Shen, Y.; Yang, T.; Lee, C.; Fu, D.; Agarwal, A.; Le, T. T.; Tsapatsis, M.; Palmer, J. C.; Weckhuysen, B. M.; Dauenhauer, P. J.; Zou, X.; Rimer, J. D. Finned Zeolite Catalysts. Nat. Mater. 2020, 19, 1074-1080.

\section{Table of Contents Graphic}

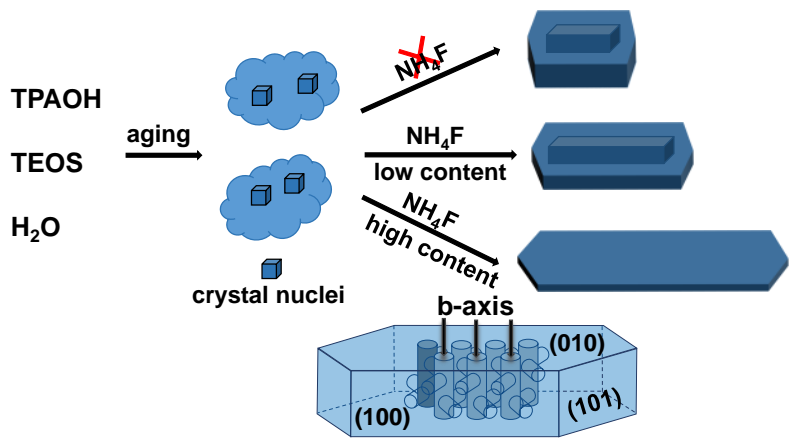

